\title{
EXPERIMENTAL ANIMAL MODELS OF PARKINSON'S DISEASE: AN OVERVIEW
}

\author{
MOHD IMRAN, ANURADHA MISHRA*, AFREEN USMANI, ASIF EQBAL
}

Department of Pharmacology, Faculty of Pharmacy, Integral University, Dasauli, Kursi Road, Lucknow, Uttar Pradesh, India. Email: misra.anuradha@gmail.com

Received: 20 July 2020, Revised and Accepted: 04 September 2020

ABSTRACT

Parkinson's disease (PD) is the $2^{\text {nd }}$ most common neurodegenerative disorder due to gradual loss of dopaminergic nerves in the substantia nigra in the midbrain which leads to motor symptoms: For instance, gait dysfunction, involuntary tremor, rigidity, and progressive postural instability. PD has no cure and available current treatment is only symptomatic. At present, the main treatment of PD relies on Levodopa that slowing down the disease development to some level but can lead to several side effects. The literature confirms the available models of Parkinsonism that is chemical-induced, that is, by 1-methyl-4-phenyl-1,2,3,6-tetrahydropyridine and 6-hydroxydopamine-induced Parkinsonism furthermore transgenic models linked to monogenic alterations in SNCA, LRRK2, UCH-L1, PRKN, and PINK1 genes. In this review article, we conclude that the presently available neurotoxic models of PD that offer a platform for neuroprotective drug discovery.

Keywords: Parkinson's disease, Neurodegenerative, Experimental models, Neurotoxin.

(c) 2020 The Authors. Published by Innovare Academic Sciences Pvt Ltd. This is an open access article under the CC BY license (http://creativecommons. org/licenses/by/4. 0/) DOI: http://dx.doi.org/10.22159/ajpcr.2020.v13i11.39131

\section{INTRODUCTION}

Parkinson's disease (PD) is a progressive neurodegenerative disorder that affects $1 \%$ of the population over 55 years of age. The pathologic hallmark of the disease is the loss of dopaminergic neurons in the Substantia Nigra pars compacta ( $\mathrm{SNpc}$ ) and the presence of intracytoplasmic inclusions named Lewy bodies, formed mainly by synuclein and ubiquitin. Dopamine (DA) replacement is the main therapy, but as PD progresses, drug-related side effects emerge as well as patient's not responses to the treatment with increased risk of side effects. Since patients with PD have a normal lifespan, they must endure crippling symptoms for many years and also a severe impact on their quality of life. Hence, therapy aims to stop the continual loss of dopaminergic neurons along with preceding disease progression. This can be achieved only by neuroprotective strategies. The neuroprotection requires early intervention in the course of the disease. Later interventions that attempt to sustain or reconstruct the nigrostriatal system should be regarded as regenerative or restorative strategies instead of neuroprotective. Some of the signs are including all following characteristics: (1) Gradual loss of DA neurons in adulthood; (2) easily detectable motor deficits; (3) development of Lewy bodies; (4) based on a single mutation; and (5) short time course [1].

Parkinson characterized by the slow and gradual degeneration of dopaminergic neurons in the SN compacta and leads to a reduce level of DA in the striatum, tailed nuclei, and the putamen [2]. The progressive loss of dopaminergic neurons in the basal complexes is the most important pathological finding in the patient's brain. Destruction of these neurons results in the DA level in this area. After $50-60 \%$ of dopaminergic neurons are degraded and DA levels in the striatum decrease by around $80-85 \%$, the symptoms of the disease appear as shown in Fig. 1. The exact molecular mechanism of the degradation of dopaminergic neurons and the incidence of PD is unclear; however, studies have shown that oxidative stress and mitochondrial dysfunction probably play a key role in the pathogenesis of PD; the loss of nigrostriatal dopaminergic neurons and the presence of intracellular cytoplasmic proteins, that is, Lewy bodies, are also involved. The cells are located in the nigrostriatal neurons in the SNpc are sent to putamen. The absence of these neurons, which typically contain small amounts of melanin, leads to depigmentation of SNpc [2]. The diagnosis of PD was based on two or more cardinal signs of PD, including resting tremor, cogwheel rigidity, bradykinesia, and postural reflex instability, and responsiveness to levodopa therapy. Risk factor of PD includes age, heredity, and exposure to neurotoxins.

\section{ETIOLOGY}

- Degeneration of neurons in the substantia nigra pars compacta.

- Degeneration of nigrostriatal (dopaminergic) tract results in a deficiency of DA in striatum $>80 \%$ (Fig. 2).

- Inequity between the excitatory amino acids acetylcholine and inhibitory neurotransmitter DA described in Fig. 3.

- Oxidation of DA in the presence of iron o Generally quenched by glutathione.

o Aging related alterations - DNA and lipid membranes.

- Genetic

o $\quad \alpha$-synuclein (synaptic protein).

o Parkin (a ubiquitin protein ligase)

o UCHL1.

o DJ-1 protein.

- Environmental causes

o Infectious mediators - Encephalitis lethargica.

o Environmental toxins -1-methyl-4-phenyl-1,2,3,6 tetrahydropyridine (MPTP).

o Acquired brain injury.

- Excitotoxicity

o $\uparrow$ Glutamate, the normal excitatory transmitter in neurons.

o Activated NMDA receptor.

o $\quad \mathrm{Ca}^{++}$load $\uparrow$.

- $\quad$ Energy metabolism and aging

o $\quad \downarrow$ Role of (mitochondrial-electron transport system and MPTP) complex.

o $\uparrow$ Oxidative stress by free radicals.

- Other common factors

o Cerebral atherosclerosis.

o Viral encephalitis.

o Due to the SIDE effects of some antipsychotic drugs (i.e., phenothiazines, butyrophenones, and reserpine).

o As a result of pesticides, herbicides, and industrial chemicals.

\section{ANIMAL MODELS OF PD}

Animal models are a vital aid to find out the preliminary pathogenic tool and therapeutic strategies for clinical disorders. For model use 


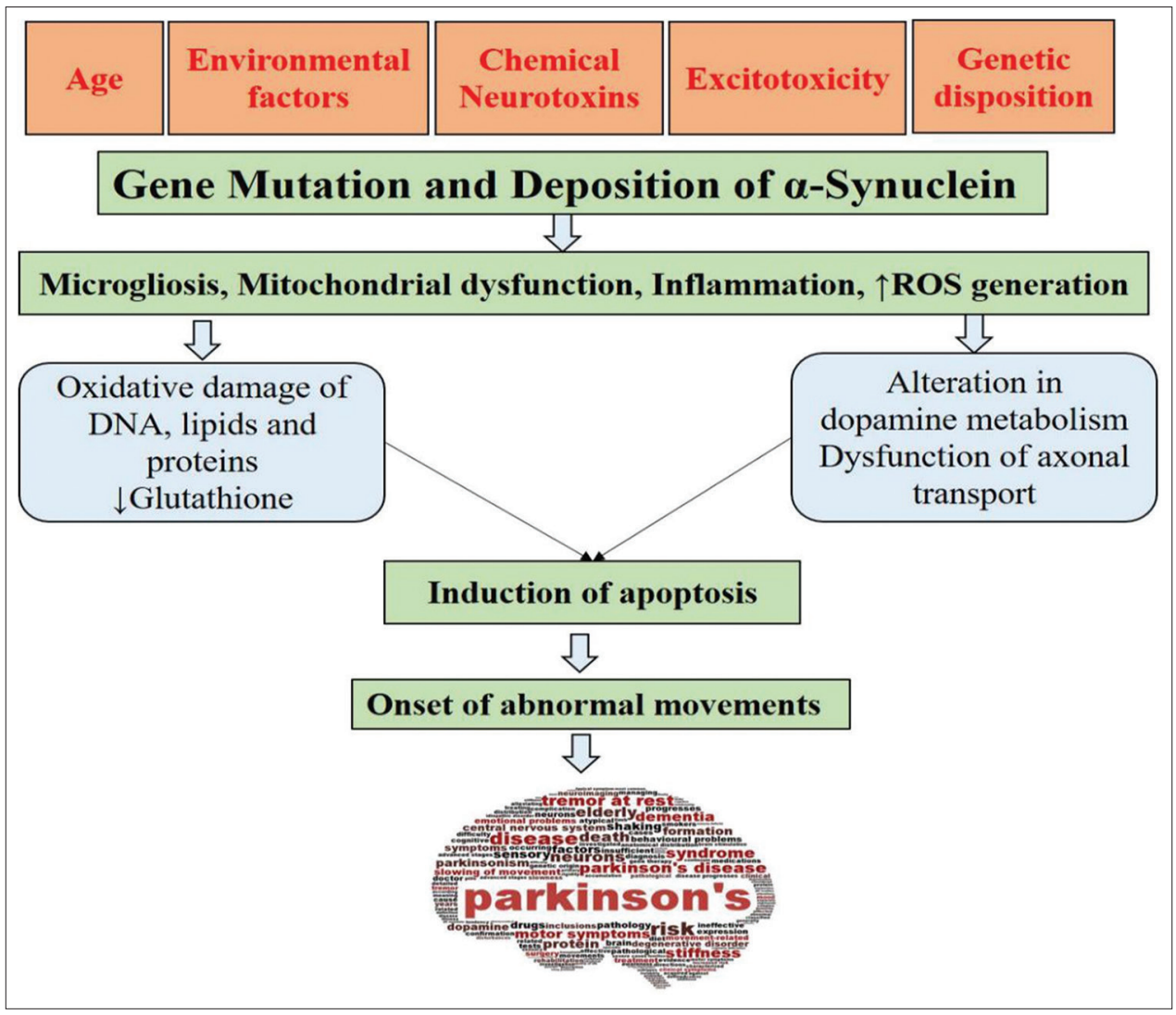

Fig. 1: General steps involved in pathophysiology of Parkinson's disease

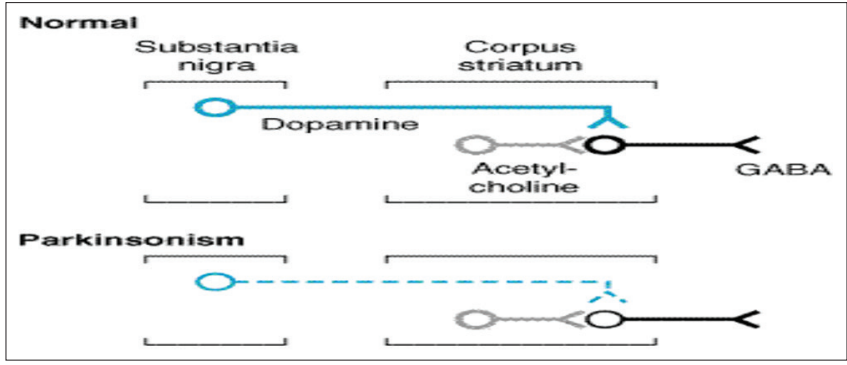

Fig. 2: Deficiency of dopamine in striatum

of an animal model confirms the striatal DA deficiency associated Parkinsonian symptoms. The Levodopa (L-DOPA) was first use to compensate for striatal DA loss. L-DOPA still remains the standard treatment of PD [3]. There are multiple animal models of PD, but the vast majority of electrophysiological data used the monoaminergic neuron-selective toxins 6-hydroxydopamine (6-OHDA) and MPTP. 6-OHDA moves into neurons through monoamine transporters, where it undergoes oxidation to toxic free radicals [4]. It is infused directly into the brain; however, it cannot cross the blood-brain barrier. If targeted to the medial forebrain region, it causes complete DA denervation at the ipsilateral hemisphere. It can also be injected into monoaminergic terminal, cause death of all neurons projecting into those areas [5]. This may confine DA loss to specific nuclei, though dopaminergic cell bodies often send collaterals to multiple regions. This is an important consideration of neuronal death, which may progress over 2 weeks or longer [6]. The MPTP model emerged after i.v. drug users inadvertently produced MPTP from meperidine and developed acute Parkinsonism [7]. MPTP produces DOPA-responsive Parkinsonism in primates and causes severe monoaminergic depletion, specifically in mice but not in rats [5]. MPTP can be administered systemically or through intracarotid infusion to primates and can be used to create Hemiparkinsonism. MPTP-treated

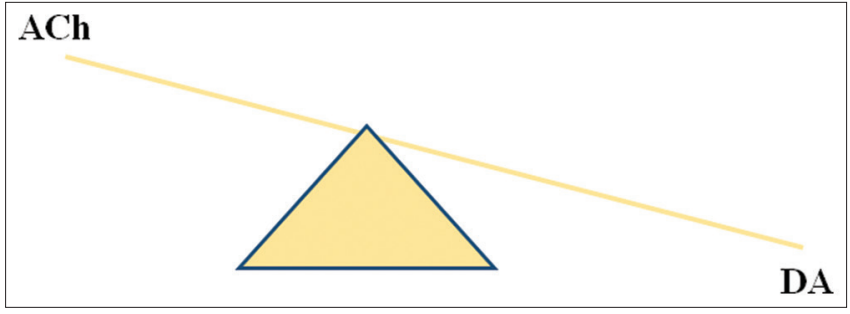

Fig. 3: Imbalance between acetylcholine and dopamine

animals demonstrate regional differences in striatal dopaminergic denervation, dopaminergic cell death, and noradrenergic cell death, similar to PD. Some primate species (notably African Green monkeys) develop a classic rest tremor, while others (notably macaques) develop an intermittent higher frequency postural/action tremor [8] The detail about the chemical induced model was mentioned in Table 1.

\section{MPTP model}

MPTP is the tool of choice for investigations of the mechanisms involved in the death of DA neurons in PD. MPTP has been shown to be toxic in a large range of species. The most popular species, besides primates, is the mouse and rats were found to be resistant to this toxin [9]. A quantity of intoxication regimes or direction methods had been used in mouse $[10,11]$ and in primates [12-14] for years; MPTP primarily causes damage to the nigrostriatal DA pathway with a profound loss of DA in the striatum and SNc [7].

In 1982, the dopaminergic neurotoxin MPTP, an analog of the narcotic meperidine (Demerol), was accidentally discovered [15]. Young drug addicts developed an idiopathic Parkinsonian syndrome after intravenous administration of (MPPP: 1-methyl-4-phenyl-propionoxypiperidine) known as a "synthetic heroin" $[15,16]$. MPTP was the neurotoxic contaminant liable for the effect. Most of the biochemical, 
neuropathological, and clinical characteristics observed in these addicted groups matched exactly to the cardinal symptoms of PD as in human with the exception of formed Lewy bodies [15]. A more recent study of these patients provided evidence for a stable and irreversible PD induced by MPTP [17]. Today, MPTP represents the most important and frequently used Parkinsonian toxin used in preclinical models $[18,19]$ and has a competitive advantage over all other toxic PD models because: (i) It cause directed a specific intoxication of dopaminergic structures and (ii) induces similar virtual symptoms as found in human PD [19]. MPTP is extremely lipophilic and after systemic administration speedily crosses the blood-brain barrier. Then after, the 1-methyl4-phenyl-2,3-dihydropyridium is formed by protoxin MPTP in nondopaminergic cells (particularly in astrocytes and serotonergic neurons) by monoamine oxidase B (MAO-B) and then extemporaneously oxidizes to $1-\mathrm{s}\left(\mathrm{MPP}^{+}\right)[19,20]$. Thereafter, $\mathrm{MPP}^{+}$is released into the extracellular space by an unidentified mechanism. The polar molecule $\mathrm{MPP}^{+}$is not able to enter dopaminergic cells freely; thus, its uptake depends on active plasma membrane carrier systems.

\section{MPP}

The uptake of $\mathrm{MPP}^{+}$, the active metabolite of neurotoxin MPTP, was studied in various mammalian cell lines transfected with the cloned human and rat DA transporters and compared with rat striatal synaptosome preparations. Only in neuronally derived cell lines such as NGIOS-15, NSPOY, and SK-N-MC cells, $\mathrm{MPP}^{+}$for the cloned transporters comparable to that of DA as seen in rat striatal synaptosomes. In nonneuronally derivative cells such as COS-7, CHO, and Ltk- cells rapidly or forever stating the transporters, the $\mathrm{K}$, of $\mathrm{MPP}^{+}$was 10 -fold higher. The everlasting expression of either the duplicated human or rat DA transporters conferred to SK-N-MC cells exposure to the cytotoxic effects of $\mathrm{MPP}^{+}$in low concentrations. The extent of this action was depend on the apparent level of the DA transporters and could be exactly antagonized by the catecholamine acceptance inhibitor mazindol. There were no substantial alterations in the susceptibility to $\mathrm{MPP}^{+}$of cells stating similar levels of either the human or rat DA transporter. The demo for the $1^{\text {st }}$ time of a quantifiable connection between the cellular appearance of the plasma membrane transporter and the level of the cytotoxic actions of $\mathrm{MPP}^{+}$advises that known alterations in the susceptibility of various brain areas to $\mathrm{MPP}^{+}$cytotoxicity might be associated to their actual content of DA uptake regions.
In addition, the intrinsic differences in the DA transporter proteins of humans and rats are not probably liable for the marked amplified susceptibility of primates to the neurotoxic effects of MPTP, as compared to rats $[21,22]$

\section{6-OHDA}

6-OHDA is a hydroxylated referent of the natural neurotransmitter DA [23]. It was originally isolated by Senoh [24]. Its biological effects were reported in works [25] and confirmed that 6-OHDA induces efficient and long-lasting noradrenaline depletion in sympathetic neurons $[25,26]$. 6-OHDA is one of the most common neurotoxins used in the assessment of central catecholaminergic estimates in the nigrostriatal system through in vivo and in vitro run down models [23,27-29]. 6-OHDA induced toxicity ensuing a preferential uptake of 6-OHDA by DA and noradrenergic transporter molecules [30]. Inside neurons, 6-OHDA accumulates in the cytosol and induces cell death without apoptotic characteristics [31]. Electron-microscopic studies have provided evidence for the ability of 6-OHDA to destroy adrenergic nerve terminals after systemic injection [32,33]. Furthermore, 6-OHDA was shown to cause ultrastructural changes in lizards and rats [34]. Non-neuronalcells like adrenocortical cells in case of inlizards and rats. However, the uptake of 6-OHDA into synaptic vesicles of adrenergic terminals is not necessary for its degenerating effect because pretreatment with reserpine prevents both the reduction of tyrosine hydroxylase (TH) in sympathetically innervated organs and ultrastructural changes of adrenergic nerve endings [35]. 6-OHDA has to be injected stereotactically into the brain for better results. Other preferred injection sites are the substantia nigra, medial forebrain bundle, and striatum [36,37]. Fig. 4 represented the induction of Parkinsonism.

\section{ROTENONE}

Complex I is the first enzyme of the respiratory chain. Rotenone having a high affinity to inhibit complex [38]. It is commonly used as an organic pesticide and in lakes and reservoirs to kill nuisance fish. Since it is extremely lipophilic, it crosses biological membranes easily and not requires specific transporters (unlike MPPp) and enters the brain very rapidly [39]. The ability to inhibit complex I without significantly affecting respiration is due to the "threshold effect" seen in brain $[40,41]$. Scientist estimated the highest brain concentration of rotenone to be about $30 \mathrm{nM}$, close to that off $\mathrm{KI}$ for complex I. The

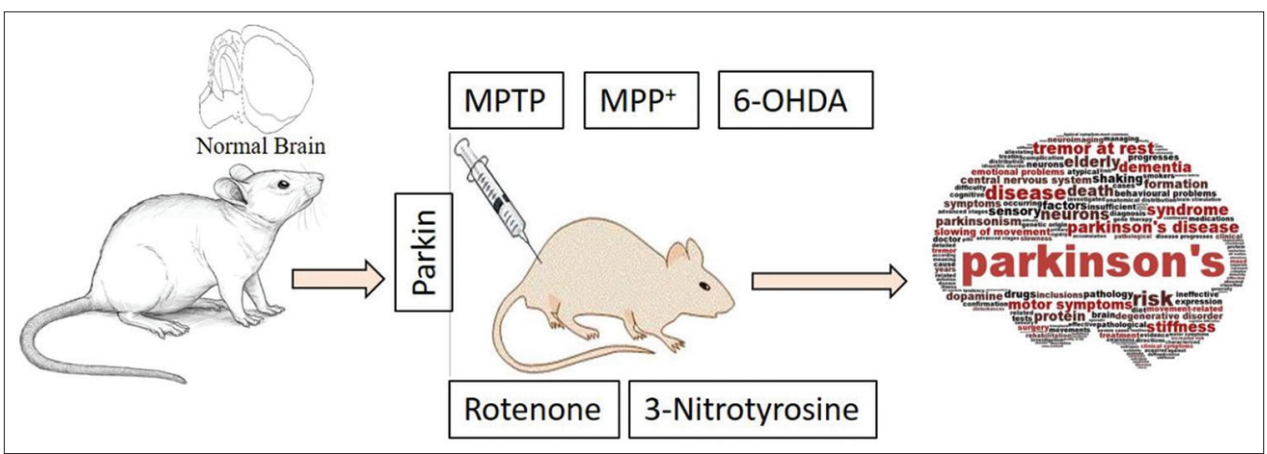

Fig. 4: Animal models showing chemical-induced Parkinsonism

Table 1: Drug tempted animal models of Parkinson's disease

\begin{tabular}{|c|c|c|c|c|c|}
\hline Sr. no. & Name of model & In vivo/In vitro & Dose & Animal used & References \\
\hline 1 & MPTP (1-methyl-4-phenyl-1,2,3,6 tetrahydropyridine) & In vivo & $15-20 \mathrm{mg} / \mathrm{kg}$ & Mice, rats, cat & {$[63,64]$} \\
\hline 2 & $\mathrm{MPP}^{+}$(1-methyl-4-phenylpyridinium) & In vivo & $0.086-0.430 \mathrm{mg} / \mathrm{kg}$ & Mice & {$[21,22,65-67]$} \\
\hline 2 & 6-OHDA (6-Hydroxydopamine) & In vivo & $0.05-0.032 \mathrm{mg} / \mathrm{kg}$ & Rats & {$[68,69]$. } \\
\hline 3 & Rotenone & In vivo & $2-3 \mathrm{mg} / \mathrm{kg}$ & Rats & {$[70,71]$} \\
\hline 4 & Transgenic $\alpha$-Synuclein & In vivo & $0.075 \mathrm{mg} / \mathrm{kg}$ & Mice & [72] \\
\hline 5 & 3-nitrotyrosine & In vivo & $0.4 \mathrm{mg} / \mathrm{kg}$ & Mice & [73] \\
\hline 6 & Reserpine & In vivo & $0.1 \mathrm{mg} / \mathrm{kg}$ & Rats, Mouse & {$[74]$} \\
\hline 8 & Amphetamine & In vivo & $2.5 \mathrm{mg} / \mathrm{kg}$ & Rats/Mice & {$[76,77]$} \\
\hline
\end{tabular}


concentration of rotenone and the degree of inhibition was uniform across brain regions and was similar in other organs such as heart, liver, and kidney.

Chronic enteric contact to rotenone in rats initiates symptoms similar to $\mathrm{PD}$, with $\mathrm{DA}$ degeneration at nigrostriatal [1]. The rotenoneadministered animal model also produces all of the behavioral features as that of human PD. Importantly, many of the degenerating neurons have intracellular inclusions that resemble Lewy bodies morphologically. These inclusions show immunoreactivity for $\alpha$-syn and ubiquitin as did the original Lewy bodies [42]. Rotenone can be administered by intraperitoneal injection, intravenous and subcutaneous injection [43]. Recently, rotenone has also tested in mice through direct infusion to the brain [44].

\section{RESERPINE}

Reserpine is an irreversible inhibitor of the vesicular monoamine transporter 2. The obstruction of DA vesicular acceptance results in the growth of neurotoxic DA oxidation byproducts [45]. DA along with molecular oxygen form DA-quinones, which can reduce the antioxidant levels mainly glutathione produces reactive oxygen species (ROS) throughout this process [46]. In addition, enzymatic breakdown of DA (through MAO) it increases the formation of ROS [47]. Oxidative damage occurs when the production of ROS exceeds the ability of the antioxidant system [48]. Furthermore, it showed that L-DOPA administration alleviated the reserpine-induced akinetic state, indicating that behavioral recovery is levodopa dependent. This led to the major hypothesis, later confirmed in humans [49], that the motor symptoms of PD result from striatal DA depletion [50]. The discovery that striatal DA deficiency resulted in PD like symptoms prompted the development of the "reserpine animal model." Systemic reserpine administration depletes the stores of DA at the nerve terminals and induces hypokinetic state in rodents. These moments deficits are due to the loss of DA storage capacity in intracellular vesicles [51].

\section{PARKIN}

Parkin is an E3 ubiquitin ligase that functions in the ubiquitinproteasome system. Mutations in parkin are a cause of familial PD and are also seen in some young, sporadic PD cases [52,53]. Several parkin mice have been generated, typically produced by deletionatexon3, exon7, or exon 2 in the PRKN gene [54-59]. However, they show no substantial DA-related behavioral abnormalities. Some of these KO mice exhibited impaired DA release [55,60] and reduced norepinephrine levels in the olfactory bulb and spinal cord with an irregular nigrostriatal area but without damage of SNc neurons [54]. Only the parkin-Q311XDAT-BAC mice exhibit multiple late onsets and progressive hypokinetic motor deficits, age-dependent DA neuron degeneration in the SNc and a significant reduction in striatal DA and dopaminergic terminals in the striatum [61]. Recently, overexpression of T240R-parkin and of human WT parkin induced progressive and dose-dependent DA cell death in rats [62].

\section{DISCUSSION}

Experimental Parkinsonism was incited in animals through various neurotoxins such as MPTP, 1-methyl-4-phenylpyridinium $\left(\mathrm{MPP}^{+}\right)$, 6-OHDA, Rotenone, 3-Nitrotyrosine, and Parkin. They induce selective dopaminergic neuron death or defects by producing increasing ROS. Further on continuation administration of neurotoxin causes aggregation of alpha synuclein. Further PD induced by genetic approaches, it includes transgenic models and viral vector-mediated models based on genes linked to monogenic PD. Environment affects the manifestation of symptoms and neurodegenerative scantling in animal models. These models can be combined to study the relationship between genetics and environment and untangle the heterogeneity and mechanisms underlying PD.

\section{CONCLUSION}

In this review article, we provide a comprehensive summary of the current experimental animal models of Parkinsonian disease. By retrieving and analyzing relevant literature, we found that a numerous neurotoxin drug, that is, MPTP, MPP+, 6-OHDA, rotenone, transgenic $\alpha$-Synuclein, 3-nitrotyrosine, reserpine, parkin, amphetamine, etc., is available which provide a platform for anti-Parkinsonism drug discovery.

\section{ACKNOWLEDGMENT}

The authors offer their sincere thanks to Dean R\&D Integral University for providing technical support and assigning Communication reference no IU/R\&D/2020-MCN000928 for further communication; we also extend our sincere thanks to Head and Dean Faculty of Pharmacy, Integral University, Lucknow.

\section{CONFLICTS OF INTEREST}

The authors affirm no conflicts of interest, financial, or otherwise.

\section{AUTHORS' CONTRIBUTIONS}

All authors take considerably subsidized to the writing of this review article. Mohd Imran, who is the first author and Asif Iqbal, the last author, has collected all the relevant literature and sorted the significant articles for this review. Dr. Anuradha Mishra, the second author, recommended the theme and helps out in collection and screening of the information in the article and reviewed the article for final submission. Ms. Afreen Usmani, the third author, played a critical part in this article who edited the article for improved graphics and assisted in the concluding endorsement for publication version.

\section{CONSENT FOR PUBLICATION}

Not applicable.

\section{AUTHORS' FUNDING}

Nil.

\section{DECLARATION OF INTEREST}

The authors declare no conflicts of interest.

\section{REFERENCES}

1. Betarbet R, Sherer TB, MacKenzie G, Garcia-Osuna M, Panov AV, Greenamyre JT. Chronic systemic pesticide exposure reproduces features of Parkinson's disease. Nat Neurosci 2000;3:1301-6.

2. Gibb WR, Lees AJ. The relevance of the Lewy body to the pathogenesis of idiopathic Parkinson's disease. J Neurol Neurosurg Psychiatry 1988:51:745-52.

3. Arvid C, Lindqvist M, Magnusson TO. 3,4-dihydroxyphenylalanine and 5-hydroxytryptophan as reserpine antagonists. Nature 1957;180:1200.

4. William D, Przedborski S. Parkinson's disease: Mechanisms and models. Neuron 2003;39:889-909.

5. Angela CM, Whishaw IQ, Schallert T. Animal models of neurological deficits: How relevant is the rat? Nat Rev Neurosci $2002 \cdot 3 \cdot 574-9$.

6. Blandini F, Levandis G, Bazzini E, Nappi G, Armentero MT. Timecourse of nigrostriatal damage, basal ganglia metabolic changes and behavioural alterations following intrastriatal injection of 6-hydroxydopamine in the rat: New clues from an old model. Eur J Neurosci 2007;25:397-405.

7. Dauer W, Przedborski S. Parkinson's disease: Mechanisms and models. Neuron 2003;39:889-909.

8. Rivlin-Etzion M, Elias S, Heimer G, Bergman H. Computational physiology of the basal ganglia in Parkinson's disease. In: Progress in Brain Research. Vol. 183. Netherlands: Elsevier; 2010. p. 259-73.

9. Chiueh CC, Markey SP, Burns RS, Johannessen JN, Jacobowitz DM, Kopin IJ. Neurochemical and behavioral effects of 1-methyl-4phenyl-1, 2, 3, 6-tetrahydropyridine (MPTP) in rat, guinea pig, and monkey. Psychopharmacol Bull 1984;20:548-53

10. Jackson-Lewis V, Przedborski S. Protocol for the MPTP mouse model 
of Parkinson's disease. Nat Protoc 2007;2:141

11. Meredith GE, Totterdell S, Potashkin JA, Surmeier DJ. Modellering PD pathogenese bij muizen: Voordelen van een chronisch MPTP-protocol. Parkinsonisme Relat Disord 2008;14:S112-5.

12. Bezard E, Imbert C, Deloire X, Bioulac B, Gross CE. A chronic MPTP model reproducing the slow evolution of Parkinson's disease: Evolution of motor symptoms in the monkey. Brain Res 1997;766:107-12.

13. Blesa J, Pifl C, Sánchez-González MA, Juri C, García-Cabezas MA, Adánez R, et al. The nigrostriatal system in the presymptomatic and symptomatic stages in the MPTP monkey model: A PET, histological and biochemical study. Neurobiol Dis 2012;48:79-91.

14. Porras G, Li Q, Bezard E. Modeling Parkinson's disease in primates: The MPTP model. Cold Spring Harb Persp Med 2012;2:a009308.

15. Langston JW, Ballard PA Jr. Parkinson's disease in a chemist working with 1-methyl-4-phenyl-1, 2, 5, 6-tetrahydropyridine. N Engl J Med 1983;309:310

16. Davis GC, Williams AC, Markey SP, Ebert MH, Caine ED, Reichert CM, et al. Chronic parkinsonism secondary to intravenous injection of meperidine analogues. Psychiatry Res 1979;1:249-54.

17. Langston JW, Forno LS, Tetrud J, Reeves AG, Kaplan JA, Karluk D. Evidence of active nerve cell degeneration in the substantia nigra of humans years after 1-methyl-4-phenyl-1, 2, 3, 6-tetrahydropyridine exposure. Ann Neurol 1999;46:598-605.

18. Beal MF. Mitochondria, oxidative damage, and inflammation in Parkinson's disease. Ann N Y Acad Sci 2003;991:120-31.

19. Przedborski S, Vila A. A tool to explore the pathogenesis of Parkinson's disease. Doc Page 2003;991:189-98.

20. Nicklas WJ, Vyas I, Heikkila RE. Inhibition of NADH-linked oxidation in brain mitochondria by 1-methyl-4-phenyl-pyridine, a metabolite of the neurotoxin, 1-methyl-4-phenyl-1, 2, 5, 6-tetrahydropyridine. Life Sci $1985 ; 36: 2503-8$.

21. Geng X, Tian X, Tu P, Pu X. Neuroprotective effects of echinacoside in the mouse MPTP model of Parkinson's disease. Eur J Pharmacol 2007:564:66-74.

22. Kim HG, Ju MS, Shim JS, Kim MC, Lee SH, Huh Y, et al. Mulberry fruit protects dopaminergic neurons in toxin-induced Parkinson's disease models. Br J Nutr 2010;104:8-16

23. Blum D, Torch S, Lambeng N, Nissou MF, Benabid AL, Sadoul R, et al. Molecular pathways involved in the neurotoxicity of 6-OHDA, dopamine and MPTP: Contribution to the apoptotic theory in Parkinson's disease. Prog Neurobiol 2001;65:135-72.

24. Senoh S, Witkop B. Non-enzymatic conversions of dopamine to norepinephrine and trihydroxyphenethylamines1. J Am Chem Soc $1959 ; 81: 6222-31$

25. Porter CC, Totaro JA, Stone CA. Effect of 6-hydroxydopamine and some other compounds on the concentration of norepinephrine in the hearts of mice. J Pharmacol Exp Ther 1963;140:308-16.

26. Porter CC, Totaro JA, Burcin A. The relationship between radioactivity and norepinephrine concentrations in the brains and hearts of mice following administration of labeled methyldopa or 6-hydroxydopamine. J Pharmacol Exp Ther 1965;150:17-22.

27. Sachs C, Jonsson G. Mechanisms of action of 6-hydroxydopamine. Biochem Pharmacol 1975;24:1-8.

28. Ungerstedt U. 6-Hydroxy-dopamine induced degeneration of central monoamine neurons. Eur J Pharmacol 1968;5:107-10

29. Ungerstedt U. 6-hydroxydopamine-induced degeneration of the nigrostriatal dopamine pathway: The turning syndrome. Pharmacol Ther B 1976;2:37-40.

30. Luthman J, Fredriksson A, Sundström E, Jonsson G, Archer T. Selective lesion of central dopamine or noradrenaline neuron systems in the neonatal rat: Motor behavior and monoamine alterations at adult stage. Behav Brain Res 1989;33:267-77.

31. Jeon BS, Jackson-Lewis V, Burke RE. 6-hydroxydopamine lesion of the rat substantia nigra: Time course and morphology of cell death. Neurodegeneration 1995;4:131-7.

32. Thoenen H, Tranzer JP. Chemical sympathectomy by selective destruction of adrenergic nerve endings with 6-hydroxydopamine. Naunyn Schmiedebergs Arch Für Pharmakol Exp Pathol 1968;261:271-88.

33. Tranzer JP, Thoenen H. An electron microscopic study of selective, acute degeneration of sympathetic nerve terminals after administration of 6-hydroxydopamine. Experientia 1968;24:155-6.

34. Unsicker K, Allan IJ, Newgreen DF. Extraneuronal effects of 6-hydroxydopamine and extraneuronal uptake of noradrenaline. Cell Tissue Res 1976;173:45-69.

35. Thoenen H. Surgical, immunological and chemical sympathectomy their application in the investigation of the physiology and pharmacology of the sympathetic nervous system. In: Catecholamines.
Berlin, Heidelberg: Springer; 1972. p. 813-44

36. Perese DA, Ulman J, Viola J, Ewing SE, Bankiewicz KS. A 6-hydroxydopamine-induced selective parkinsonian rat model. Brain Res 1989;494:285-93.

37. Przedbroski S, Leviver M, Jiang H, Ferreira M, Jackson-Lewis V, Donaldson $\mathrm{D}$, et al. Dose-dependent lesions of the dopaminergic nigrostriatal pathway induced by instrastriatal injection of 6-hydroxydopamine. Neuroscience 1995;67:631-47.

38. Esposti DM. Inhibitors of NADH-ubiquinone reductase: An overview. Biochim Biophys Acta 1998;1364:222-35.

39. Talpade DJ, Greene JG, Higgins DS Jr., Greenamyre JT. In vivo labeling of mitochondrial complex i (NADH:Ubiquinone oxidoreductase) in rat brain using [3h] dihydrorotenone. J Neurochem 2000;75:2611-21.

40. Davey GP, Clark JB. Threshold effects and control of oxidative phosphorylation in nonsynaptic rat brain mitochondria. J Neurochem 1996;66:1617-24.

41. Higgins DS Jr., Greenamyre JT. [3H] dihydrorotenone binding to NADH: Ubiquinone reductase (complex I) of the electron transport chain: An autoradiographic study. J Neurosci 1996;16:3807-16

42. Betarbet R, Sherer TB, MacKenzie G, Garcia-Osuna M, Panov AV, Greenamyre JT. Chronic systemic pesticide exposure reproduces features of Parkinson's disease. Nat Neurosci 2000;3:1301-6.

43. Sherer, TB, Kim JH, Betarbet R, Greenamyre JT. Subcutaneous rotenone exposure causes highly selective dopaminergic degeneration and $\alpha$-synuclein aggregation. Exp Neurol 2003;179:9-16.

44. Fleming SM, Zhu C, Fernagut PO, Mehta A, DiCarlo CD, Seaman RL, et al. Behavioral and immunohistochemical effects of chronic intravenous and subcutaneous infusions of varying doses of rotenone. Exp Neurol 2004; 187:418-29.

45. Pan-Montojo F, Anichtchik O, Dening Y, Knells L, Pursche S, Jung R, et al. Progression of Parkinson's disease pathology is reproduced by intragastric administration of rotenone in mice. Nat Prec 2009;29:1480-5.

46. Caudle WM, Colebrooke RE, Emson PC, Miller GW. Altered vesicular dopamine storage in Parkinson's disease: A premature demise. Trends Neurosci 2008;31:303-8.

47. Tsang AH, Chung KK. Oxidative and nitrosative stress in Parkinson's disease. Biochim Biophys Acta 2009;1792:643-50.

48. Lohr JB. Oxygen radicals and neuropsychiatric illness: Some speculations. Arch Gene Psychiatry 1991;48:1097-106.

49. Droge W. Free radicals in the physiological control of cell function. Physiol Rev 2002;82:47-95.

50. Hornykiewicz O. Die topische lokalization und des verhalten von noradrenalin und dopamin (3-hydroxytyramin) in der substantia nigra der normalen und Parkinson kranken Menschen. Wien Klin Wochschr 1963;75:309-12.

51. Bernheimer $\mathrm{H}$, Birkmayer $\mathrm{W}$, Hornykiewicz $\mathrm{O}$, Jellinger $\mathrm{K}$, Seitelberger F. Brain dopamine and the syndromes of Parkinson and Huntington clinical, morphological and neurochemical correlations. $\mathrm{J}$ Neurol Sci 1973;20:415-55.

52. Hornykiewicz O. Dopamine (3-hydroxytyramine) and brain function. Pharmacol Rev 1966;18:925-64.

53. Lücking CB, Dürr A, Bonifati V, Vaughan J, De Michele G, Gasser T, et al, The French Parkinson's Disease Genetics Study Group; European Consortium on Genetic Susceptibility in Parkinson's Disease. Association between early-onset Parkinson's disease and mutations in the parkingene. N Engl J Med 2000;342:1560-7.

54. Periquet M, Latouche M, Lohmann E, Rawal N, De Michele G, Ricard $\mathrm{S}$, et al. Parkin mutations are frequent in patients with isolated early-onset parkinsonism. Brain 2003;126:1271-8.

55. Goldberg MS, Fleming SM, Palacino JJ, Cepeda C, Lam HA, Bhatnagar A, et al. Parkin-deficient mice exhibit nigrostriatal deficits but not loss of dopaminergic neurons. J Biol Chem 2003;278:43628-35.

56. Jean-Michel I, Ibáñez P, Mena MA, Abbas N, Cohen-Salmon C, Bohme GA, et al. Parkin gene inactivation alters behaviour and dopamine neurotransmission in the mouse. Hum Mol Genet 2003:12:2277-91.

57. Palacino JJ, Sagi D, Goldberg MS, Krauss S, Motz C, Wacker M, et al. Mitochondrial dysfunction and oxidative damage in parkin-deficient mice. J Biol Chem 2004:279:18614-22.

58. Perez FA, Palmiter RD. Parkin-deficient mice are not a robust model of parkinsonism. Proc Natl Acad Sci 2005;102:2174-9.

59. Xin-Ran Z, Maskri L, Herold C, Bader V, Stichel CC, Güntürkün O, et al. Non-motor behavioural impairments in parkin-deficient mice. Eur J Neurosci 2007;26:1902-11

60. Martella G, Platania P, Vita D, Sciamanna G, Cuomo D, Tassone A, et al. Enhanced sensitivity to Group II mGlu receptor activation at corticostriatal synapses in mice lacking the familial parkinsonism- 
linked genes PINK1 or Parkin. Exp Neurol 2009;215:388-96.

61. Kitada T, Pisani A, Porter DR, Yamaguchi H, Tscherter A, Martella G, et al. Impaired dopamine release and synaptic plasticity in the striatum of PINK1-deficient mice. Proc Natl Acad Sci 2007;104:11441-6.

62. Xiao-Hong L, Fleming SM, Meurers B, Ackerson LC, Mortazavi F, Lo $\mathrm{V}$, et al. Bacterial artificial chromosome transgenic mice expressing a truncated mutant parkin exhibit age-dependent hypokinetic motor deficits, dopaminergic neuron degeneration, and accumulation of proteinase K-resistant $\alpha$-synuclein. J Neurosci 2009;29:1962-76.

63. Van Rompuy AS, Lobbestael E, Van der Perren A, Van den Haute C, Baekelandt V. Long-term overexpression of human wild-type and T240R mutant parkin in rat substantia nigra induces progressive dopaminergic neurodegeneration. J Neuropathol Exp Neurol 2014;73:159-74.

64. Fujikawa T, Shinji M, Kanada N, Nakai N, Ogata M, Suzuki I, et al. Acanthopanax senticosus harms as a prophylactic for MPTP-induced Parkinson's disease in rats. J Ethnopharmacol 2005;97:375-81.

65. Patricia R, Serrano-García N, Medina-Campos ON, Pedraza-Chaverri J, Maldonado PD, Ruiz-Sánchez E. S-allylcysteine, a garlic compound, protects against oxidative stress in 1-methyl-4-phenylpyridiniuminduced parkinsonism in mice. J Nutr Biochem 2011;22:937-44

66. Radad K, Gille G, Moldzio R, Saito H, Ishige K, Rausch WD. Ginsenosides $\mathrm{Rb} 1$ and $\mathrm{Rg} 1$ effects on survival and neurite growth of MPP+-affected mesencephalic dopaminergic cells. J Neural Transm 2004; $111: 37-45$.

67. Chen J, Tang XQ, Zhi JL, Cui Y, Yu HM, Tang EH, et al. Curcumin protects PC12 cells against 1-methyl-4-phenylpyridinium ion-induced apoptosis by bcl-2-mitochondria-ROS-iNOS pathway. Apoptosis 2006;11:943-53.

68. Kim IS, Choi DK, Jung HJ. Neuroprotective effects of vanillyl alcohol in Gastrodia elata blume through suppression of oxidative stress and anti-apoptotic activity in toxin-induced dopaminergic MN9D cells. Molecules 2011;16:5349-61.

69. Kai Z, Ma Z, Wang J, Xie A, Xie JX. Myricetin attenuated MPP+- induced cytotoxicity by anti-oxidation and inhibition of MKK4 and JNK activation in MES23. 5 cells. Neuropharmacology 2011;61:329-35.

70. Yamaratee J, Thampithak A, Meesarapee B, Ratanachamnong P, Suksamrarn A, Phivthong-Ngam L, et al. Curcumin I protects the dopaminergic cell line SH-SY5Y from 6-hydroxydopamine-induced neurotoxicity through attenuation of p53-mediated apoptosis. Neurosci Lett 2011;489:192-6.

71. Ye-Ming L, Jiang B, Bao YM, An LJ. Protocatechuic acid inhibits apoptosis by mitochondrial dysfunction in rotenone-induced PC12 cells. Toxicol in Vitro 2008;22:430-7.

72. Molina-Jiménez, Francisca M, Sánchez-Reus MI, Cascales M, Andrés D, Benedí J. Effect of fraxetin on antioxidant defense and stress proteins in human neuroblastoma cell model of rotenone neurotoxicity. Comparative study with myricetin and $\mathrm{N}$-acetylcysteine. Toxicol Appl Pharmacol 2005;209:214-25.

73. Kostas V, Xilouri M, Emmanouilidou E, Rideout HJ, Stefanis L. Pathological roles of $\alpha$-synuclein in neurological disorders. Lancet Neurol 2011:10:1015-25

74. Khaled R, Moldzio R, Taha M, Rausch WD. Thymoquinone protects dopaminergic neurons against MPP+ and rotenone. Phytother Res 2009:23:696-700

75. Takahiko F, Kanada N, Shimada A, Ogata M, Suzuki I, Hayashi I, et al. Effect of sesamin in Acanthopanax senticosus H ARMS on behavioral dysfunction in rotenone-induced parkinsonian rats. Biol Pharm Bull 2005;28:169-72

76. Lu XH, Fleming SM, Meurers B, Ackerson LC, Mortazavi F, Lo V, et al. Bacterial artificial chromosome transgenic mice expressing a truncated mutant parkin exhibit age-dependent hypokinetic motor deficits, dopaminergic neuron degeneration, and accumulation of proteinase K-resistant $\alpha$-synuclein. J Neurosci 2009;29:1962-76.

77. Wagner GC, Seiden LS, Schuster CR. Methamphetamine-induced changes in brain catecholamines in rats and guinea pigs. Drug Alcohol Depend 1979;4:435-8. 